\title{
Smart Polymers and Coatings Obtained by Ionizing Radiation: Synthesis and Biomedical Applications
}

\author{
H. Iván Meléndez-Ortiz' ${ }^{1}$ Gustavo H. C. Varca², Ademar B. Lugão², Emilio Bucio ${ }^{3 *}$ \\ ${ }^{1}$ Departamento de Materiales Avanzados, Centro de Investigación en Química Aplicada, \\ Saltillo, México \\ ${ }^{2}$ Instituto de Pesquisas Energéticas e Nucleares-IPEN-CNEN/SP, Cidade Universitária, \\ São Paulo, Brasil \\ ${ }^{3}$ Departamento de Química de Radiaciones y Radioquímica, Instituto de Ciencias Nucleares, \\ Universidad Nacional Autónoma de México, Circuito Exterior, Ciudad Universitaria, México DF, México \\ Email: ${ }^{*}$ ebucio@nucleares.unam.mx
}

Received 27 May 2015; accepted 3 August 2015; published 6 August 2015

Copyright (C) 2015 by authors and Scientific Research Publishing Inc.

This work is licensed under the Creative Commons Attribution International License (CC BY).

http://creativecommons.org/licenses/by/4.0/

(c) (i) Open Access

\section{Abstract}

Gamma radiation has been shown particularly useful for the functionalization of surfaces with stimuli-responsive polymers. This method involves the formation of active sites (free radicals) onto the polymeric backbone as a result of the exposition to high-energy radiation, in which a proper microenvironment for the reaction among monomer and/or polymer and the active sites takes place, thus leading to propagation which forms side chain grafts. The modification of polymers using high-energy irradiation may be performed by the following methods: direct or simultaneous, pre-irradiation oxidative and pre-irradiation. The most frequent ones correspond to the pre-irradiation oxidative method and the direct one. Radiation-grafting has many advantages over conventional methods considering that it does not require catalyst nor additives to initiate the reaction, and in general, no changes on the mechanical properties with respect to the pristine polymeric matrix are observed. This chapter focused on the synthesis of smart polymers and coatings obtained by the use of gamma radiation. In addition, diverse applications of these materials in the biomedical field are also reported.

\section{Keywords}

Smart Polymers, pH Responsive, LCST, Biomedical Applications, Radiation-Grafting

\footnotetext{
${ }^{*}$ Corresponding author.
}

How to cite this paper: Meléndez-Ortiz, H.I., Varca, G.H.C., Lugão, A.B. and Bucio, E. (2015) Smart Polymers and Coatings Obtained by lonizing Radiation: Synthesis and Biomedical Applications. Open Journal of Polymer Chemistry, 5, 17-33. 


\section{Introduction}

Stimuli-responsive polymers are polymers that respond sharply to small changes in physical or chemical conditions with relatively large phase or property changes [1]. The stimuli in which smart polymers respond to are commonly classified into three categories: physical, chemical or biological [2]. Temperature and $\mathrm{pH}$ stimuliresponsive macromolecular materials have attracted great attention due to their obvious applications in biomedicine and biotechnology [3]. Some stimuli sensitive monomers exhibit separation from solution and solidification above certain temperatures; thermally-responsive polymers undergo a coil-globule transition in aqueous solution at temperature values which are known to lower critical solution temperature (LCST) [4]. In the case of sensitive polymers, the molecules are soluble below the LCST. Above this transition, they become increasingly hydrophobic and insoluble, and thus lead to gel formation. In contrast, hydrogels that are hydrophobic below critical temperature and hydrophilic above it typically present an upper critical solution temperature (UCST) [5].

Stimuli-responsive polymers are of particular interest due to their ability to undergo well defined changes in their properties [6]. Taking into account that most grafting reactions occur at the surface or in the bulk polymeric matrix, polymer grafting stands as a suitable method to synthesize such materials. Acrylic acid (AAc) is one of the most popular monomers that have been grafted onto different polymeric matrices to develop $\mathrm{pH}$ responsive materials. In this case the carboxyl groups offer sites for the coupling with amino groups terminated poly (ethylene oxide) (PEO) where, via carbodiimide activation method, they are directly used for the interaction with heparin. In general, the carboxylic group has the capability to undergo further chemical reactions to produce new functional groups [7]. The thermosensitive characteristics of poly (N-isopropylacrylamide) (NIPAAm) have been widely studied in the fields of drug delivery and tissue engineering [8]. The concept of a "smart" coating is more recent and has been applied to functional coatings that are able to respond to certain stimuli generated by intrinsic or extrinsic events [9].

Radiation synthesis of stimuli-responsive polymers and adsorbents is a wide field of important applications of radiation technology [10]. Radiation graft polymerization has been widely used for over 50 years throughout polymer chemistry. Typically, it involves the creation of reactive sites (radicals) on the polymer surface followed by covalent linkage of a preformed polymer or, more frequently by the polymerization of a monomer from those radical sites [11]. Grafting techniques present advantages over conventional approaches with regard to the development of thin functional films for several reasons. They include easy and controllable introduction of polymer chains with a high surface density, precise localization of the chain at the surface and long stability of the grafted layers among others [12].

Pharmaceutical and biological therapeutics are often limited by short half-lives, poor bioavailability, and physical or chemical instability [13]. Stimuli-responsive (self-regulated) drug delivery systems have been investigated for their applications in pulsatile delivery of certain hormone drugs. Among all systems studied, temperature and $\mathrm{pH}$-responsive delivery systems in particular have drawn much attention considering that some disease states manifest themselves by a change in temperature and/or $\mathrm{pH}$ [14]. One relevant application corresponds to the development of delivery devices based on a novel squeezing concept, which relies upon specific swellingdeswelling characteristics under specific temperatures, or temperature/pHs [15].

\section{Ionizing Radiation and Polymers}

Radical polymerization has received the greatest amount of attention among all polymerization methods. About $60 \%$ of all available polymers are still obtained by this method [16]. This highlighted position of free radical polymerization is due to its many attractive characteristics including, but not limited to [17]-[19]:

a) Its applicability to the polymerization of a wide range of vinyl monomers such as methacrylates, methacrylamides, styrene, butadiene, vinyl acetate and water-soluble monomers such as acrylic acid, the hydroxyacrylates and $\mathrm{N}$-vinyl pyrrolidone;

b) Its ability to provide an unlimited number of copolymers;

c) Its tolerance to a wide range of functional groups (e.g. $-\mathrm{OH},-\mathrm{NR}_{2}$, $-\mathrm{COOH},-\mathrm{CONR}_{2}$ ) and reaction conditions (bulk, solution, emulsion, mini-emulsion, suspension);

d) Its tolerance to water or other impurities in contrast to the great sensitivities of ionic polymerization and of coordination polymerization;

e) The possibility to perform the process under convenient, mild reaction conditions and wide temperature range. 
f) The simple and low cost implementation if compared to other technologies.

\subsection{Principles of Radiation Chemistry}

Radiation chemistry implies chemical effects of interactions of high energy ionizing radiation with materials. The result of energy absorption is the rupture or rearrangement of chemical bonds. One of the most obvious changes produced by ionizing radiation is the formation of ions. However, a significant amount of the radiation energy is also used to excite molecular electrons without extracting them from their parent molecule. Once such primary ion and excited molecules are formed they may undergo various secondary reactions including electron capture, charge neutralization, inter- and intra-molecular energy transfer processes, and molecular dissociation. Precise knowledge of the nature of the primary fragments resulting from the dissociation of molecules of the irradiated medium is of key relevance to the full understanding of radiation-chemical changes. Another specific feature of primary radiation-chemical processes lies in the fact that the primary events are not distributed randomly throughout the irradiated medium but occur in highly localized regions close to the tracks of the ionizing particles [20] [21].

\subsection{Radiation Techniques}

Radiation processing has many advantages over conventional methods. When using radiation for materials processing, neither catalysts nor additives are required in order to initiate the reaction, considering the energy source being either gamma-ray, UV or electrons [22]. The main advantage of these radiation-assisted methods is that they are relatively simple.

Surface grafting of polymers has attracted great interest in the past few decades as it allows the tailoring of surface properties of various polymer materials and thus, specific functionalities useful for many applications may be effectively produced [23].

When polymers are exposed to ionizing irradiation, trapped radicals and peroxides or hydroperoxides are formed as a result. These radicals are capable of initiating polymerization reactions. Various polymerization approaches have been developed, including direct graft polymerization of vinyl monomers that already contain desirable functional groups [20].

High-energy radiation, such as gamma-irradiation and electron beam lead to activation of polymers in a way that specific monomers may be grafted. To the extent of modification, i.e., the grafting degree may be easily controlled by careful variation of the radiation exposure and reaction conditions. The grafting method by gamma-irradiation is extremely attractive considering that the modified biomaterial is obtained in the purest form possible, no chemical initiators are required and it may be applicable to almost all polymer-monomer combinations and thus allowing enormous possibilities to generate materials with improved physical-chemical and biological characteristics [24]. Another advantage of gamma-irradiation is that it offers much higher penetration into the polymer if compared to the electron beam [25].

\subsection{Types of Polymers Obtained by Ionizing Radiation}

The irradiation of macromolecules is known to cause homolytic fission and thus form free radicals on the polymer. The medium is of key relevance in this case, e.g. if irradiation is carried out in air peroxides may be formed on the polymer. The lifetime of the free radical, on the other hand, relies upon the nature of the polymer backbone. The radiation grafting of various water-soluble monomers such as acrylic acid, methacrylic acid, acrylamide, N,N-dimethylacrylamide and $\mathrm{N}$-vinyl-2-pyrrolidone on ultra-high molecular weight polyethylene were synthesized. A large effort is being devoted to the production of membranes via grafting of various hydrophilic monomers onto polyethylene, polypropylene and fluorinated polymers, as base polymers. As an example, the irradiation grafting of dimethylaminoethymethacrylate was studied in several polymers such as polyethylene, polypropylene, polytetrafluoroethylene, silicone and polycarbonates.

\subsubsection{Radiation Induced Graft Copolymerization}

Radiation-induced graft copolymerization is a well established technology dating back almost 50 years [20] [26]. If the polymer substrate is exposed to ionizing radiation (for instance, electron beams, gamma-rays, $\mathrm{X}$-rays) the active sites randomly produced along polymer chain may act as macro-initiators and initiate free radical poly- 
merization of the monomer as a consequence. This method is applicable for a lot of polymer/monomer combinations and unlike chemically initiated grafting, there is no contamination from initiators. The extent of polymerization of monomers on substrates is expressed in terms of grafting yield, also known as grafting degree. In principle, there are three methods for radiation grafting [27] [28] which are outlined below:

\section{1) Radiation-grafting by simultaneous or mutual method}

The so called radiation-grafting by simultaneous or mutual method is perhaps the simplest one. In this case, both polymer and monomers are introduced into a reactor and simultaneously irradiated. The polymer substrate is immersed in the monomer, which may be a liquid, vapor or solid diluted in a suitable solvent, in presence or absence of additives, and then exposed to ionizing radiation. In addition to the formation of the grafted polymer a homopolymer will invariably be formed, considering that both substrate and monomer are exposed to radiation. This technique should be carried out only if the radiochemical yield of the polymer $\mathrm{G}_{(\mathrm{R}) \mathrm{P}}$ is higher than the monomer $\mathrm{G}_{(\mathrm{R} \cdot \mathrm{M})}$ in order to avoid homopolymer formation, which stands as its main disadvantage [20]. The addition of monomers in vapor phase or at low concentrations in a suitable solvent, and the use of polymerization inhibitors such as Mohr's salt may reduce such formation [29].

\section{2) Radiation-grafting by pre-irradiation method (post-irradiation grafting).}

The pre-irradiation method (post-irradiation grafting) is characterized by pre-irradiation of the polymer under vacuum or inert gas. When radiation reaches the sample, the molecules become ionized and excited species are formed. These species form relatively stable free radicals which build up the active sites. The grafting polymerization reaction is usually initiated at elevated temperatures for monomers introduced in liquid, vapor or as solution in a suitable solvent. The main advantage of this technique is that since monomers are not exposed to radiation, the homopolymer formation is low, whereas its disadvantages are attributed to the short life time of the generated radicals, the need of inert atmosphere and the low grafting yield. The grafting degree strongly depends on reaction conditions such as pre-irradiation dose, monomer concentration, temperature, reaction time, material thickness and the solvent in cases where it is applied [20] [30].

\section{3) Radiation-grafting by pre-irradiation oxidative or alkylperoxy/hydroperoxy method}

The pre-irradiation oxidative method, also known as alkylperoxy/hydroperoxy method, consists in the irradiation of samples in air or oxygen. In a more specific way the free radicals present in the polymer backbone quickly react with oxygen and then form alkylperoxides and hydroperoxides. In a second and sub-sequent step, the monomer or monomer solution is introduced and heated in absence of oxygen. Both peroxides and hydroperoxides are homolytically broken and then become available to react with the monomer. In this case, the grafting degree depends on the above mentioned conditions. The main advantage of this technique is that pre-irradiated samples may be stored at low temperature [20] [30], while the disadvantages are related to the need of elevated temperatures, long reaction time and solvents in some cases. Another drawback to be considered is related to the formation of hydroxyl radicals which may trigger homopolymerization and then lead to lower grafting yields as a consequence if compared to the simultaneous method [31], in which this reaction is absent.

Each of these methods (direct, pre-irradiation, and pre-irradiation oxidative) holds advantages and disadvantages. The existence of these methods is particularly useful when the access to a radiation source is limited. The simultaneous method in particular, requires the use of the radiation source during the entire grafting process; Whatsoever, grafting yields are generally higher when compared to the pre-irradiation methods due to reduced radical loss, which are originated from decomposition reactions present in the latter method [32]. In all cases, the rate and efficiency of the initiation is dependent upon the type of radiation, dose rate, and the radiation sensitivity of the material involved [33].

\subsubsection{RAFT-Graft Polymerization}

The RAFT-graft polymerization may be achieved by the use of gamma radiation [34]. Controlled radical polymerization, also called living free-radical polymerization is a technique that combines the advantages of free radical polymerization with living polymerization in order to obtain well-defined macromolecules [35]. Reversible addition-fragmentation chain transfer polymerization (RAFT) on the other hand, involves a reversible chain transfer rather than chain termination. In this process initiating radicals are generated by the exposition of the polymer, or monomers in solution to gamma irradiation. These radicals initiate the propagating chains which are capable of binding to RAFT agents and form intermediate radicals. In pre-equilibrium the leaving groups are released and capable of re-initiating propagation [36]. 


\section{Smart Polymers Obtained by Ionizing Radiation}

The temperature sensitive behavior of NIPAAm grafted by electron beam onto polypropylene (PP) and by the gamma pre-irradiation oxidative method was studied by Bucio [37]. NIPAAm grafted onto poly (vinyl chloride) tubes were synthesized by the gamma pre-irradiation method [38] and low LCST was found at $30^{\circ} \mathrm{C}$ with maximum graft yields near $40 \%$ and low swelling percentage of about $19 \%$. The production of temperature sensitive membranes by radiation grafting composed of NIPAAm grafted on a polyvinylidene fluoride (PVDF) porous membrane was studied by Kang [39]. The influence of radiation and reaction conditions on the grafting yield was investigated in details and the results showed that the membranes exhibited the temperature-sensitive LCST of NIPAAm. NIPAAm was also grafted by the use of the pre-irradiation method onto an ethyl-vinyl acetate copolymer (EVA), and it was found that the surface of the copolymer grafted with NIPAAm showed thermosensitivity similarly to partially crosslinked PNIPAAm gels [40]. The thermo and $\mathrm{pH}$ sensitivity behavior of 2-(dimethylamino) ethyl methacrylate and 4-vinyl pyridine binary grafted onto PP films was studied by Burillo [41]. AAc is one of the most popular monomers that have been grafted onto different polymeric matrices. Its polymer or copolymers with $\mathrm{pH}$ sensitive response and carboxylic groups from poly acrylic acid of $\mathrm{pH}$ sensitive response have a capability to undergo further chemical reactions to produce new functional groups [42].

\subsection{Temperature-Responsive Polymers}

Temperature-sensitive polymers exhibit LCST behavior where phase separation is induced at a certain temperature threshold (Figure 1). Polymers of this type undergo thermally induced reversible phase transition. They are soluble in aqueous solvents (water) at low temperatures but become insoluble as the temperature rises above the LCST. It is possible to increase the functionality of microgel particles by finding the right balance of hydrophobic and hydrophilic co-monomers or by tuning to a desired temperature range by copolymerization using more hydrophilic (which raises the LCST) or more hydrophobic (which lowers the LCST) co-monomers [43] [44].

Heskins and Gillet were the first to report an endotherm observed at the LCST upon heating an aqueous solution of PNIPAAm [45]. Grinberg [46] have studied the volume phase transition in responsive polymers using high-sensitivity differential scanning calorimetry (DSC) and as well as the swelling behavior of the polymers at different scanning rates. It was possible to measure the dependence of the transition parameters on the heating rate. The DSC measurements, by heating at different rates (from 1 to $10^{\circ} \mathrm{C} / \mathrm{min}$ ), provide results nearly approximating equilibrium and LCST or UCST. The transition temperature, enthalpy, and entropy of this thermosensitive behavior as well as the transition LCST are parameters that may be estimated.

\section{2. pH-Responsive Polymers}

pH-responsive polymers (Figure 1) consist of ionizable pendants capable of accepting and donating protons in response to environmental changes in $\mathrm{pH}$ such as carboxylic acids and basic amino alkyl moieties [47]. The

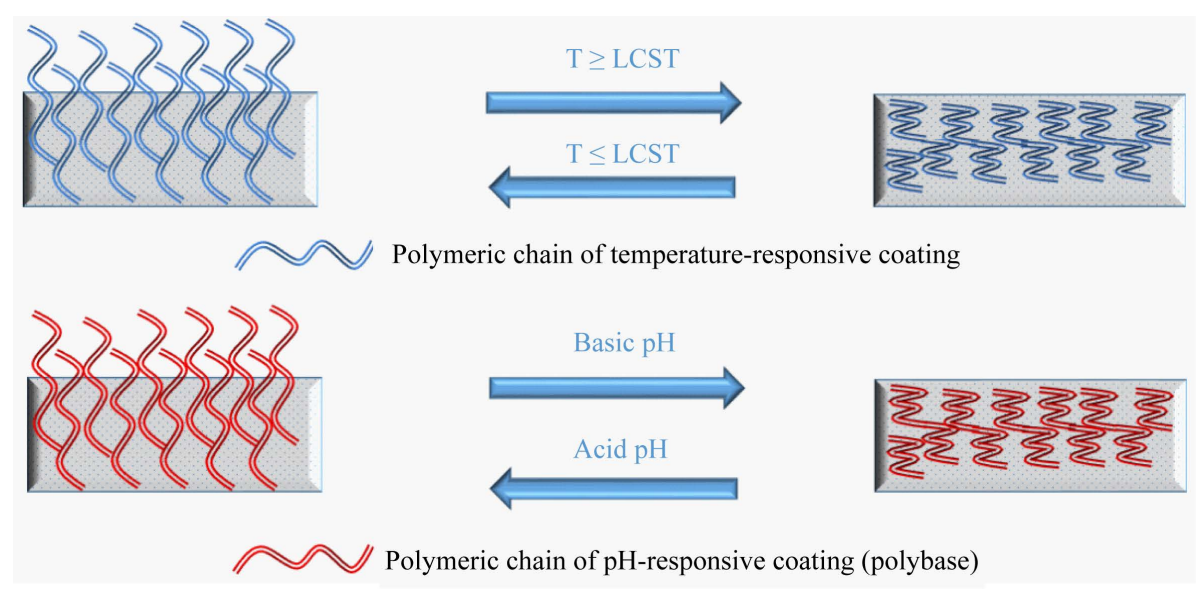

Figure 1. Representative scheme of Thermo and $\mathrm{pH}$-responsive polymeric coatings. 
change in the charge of pendant groups causes an alteration of the hydrodynamic volume of the polymer chains [48]. Then, the transition from collapsed state to swollen state is caused by the osmotic pressure generated by mobile counterions which neutralize the charges [49]. The phase transition of $\mathrm{pH}$-sensitive polymers is nominated critical $\mathrm{pH}$. In the human body $\mathrm{pH}$ variations are present along the gastrointestinal tract and in problematic sectors like tumor areas and surrounding tissues [50]. Drug delivery in this specific area makes relevant the need for the development of $\mathrm{pH}$-sensitive systems with fast response to changes in environmental stimuli. A fast response of a polymer and a repetitive function of another polymer may be combined using different functionalization techniques such as $\gamma$-irradiation. Most grafting reactions which take place on the surface or in the bulk polymeric matrix allow the design of clinically effective controlled drug delivery systems, supported by the concept of achieving optimized combinations between monomer and the polymer itself.

\subsection{Light-Responsive Polymers}

The functionalization of polymers using light-responsive materials confers the ability to respond to stimuli triggered by the exposition to light sources such as UV, Vis or infrared. Apart from the nature of the induced changes, e.g. swelling or deswelling, these light induced transitions at molecular level assure a wide range of applications, including cell culture, photonics and drug delivery systems among others [51]. Common lightresponsive materials may be achieved by the addition of photo-sensitive groups [51] such as azopyridine [52], spiropyrans [53], stilbenes [54], Triphenylmethane-leuco derivatives, bis(4-dimethylamino)phenylmethyl leucocyanide, including modified polyacrylamides [55] and azobenzene materials [56].

Light allows proper and specific control of the trigger mechanism, as well as assures precise control of the stimulus. A combination of these properties makes light-responsible systems very promising materials for drug delivery purposes. Inconsistent responses to light, uncontrolled structural changes, and slow response correspond to typical drawbacks of these materials [55]. Although these systems may hold very relevant properties for a wide variety of applications in different fields, the use of ionizing radiation for the synthesis and development of light responsive polymers and coatings is slim to none. The main reason for this is related to the high sensitivity to high energy irradiation by the monomers or functional groups to be inserted into the polymer. This makes the use of irradiation techniques not very promising for the design of such materials.

\subsection{Magnetic-Responsive Polymers}

The so-called magnetic-responsive polymers are result of the combination of polymers with magnetic particles, at nano or micro level, that hold the ability to undergo changes in response to magnetic fields, also known as magnetoelastic or magnetostrictive polymeric composites [57] [58]. On this account, a wide variety of magnetic nanoparticles have been incorporated/added to polymers by distinct methods in order to combine properties of both materials into a stable system, e.g. colloidal formulations [57] [58]. Typical particles are related but not limited to metal particles, ferromagnetic particles [59] and nickel powders [60]. These systems are more applicable and promising towards the development of advanced materials for drug targeting or site specific delivery, including magnetic devices, artificial muscles, micromanipulators and so on [57].

Composites are not the main focus of this chapter, whatsoever for further reference irradiation mediated pathways abound in literature concerning the development of both magnetic nanoparticles [61] and the composites [62] [63]. An additional feature of the use of high energy irradiation for such purpose is related to the possibility to perform both, nanoparticle synthesis and composite development, simultaneously or not.

\section{Ionizing Radiation and Coatings}

During the past 50 years, radiation processing of materials has been increasingly applied to improve quality, efficiency, energy savings and for the manufacture of new products with specific properties. Currently, radiation technology continues to enter the marketplace with innovations in materials processing. Radiation technologies applied to materials processing comprise different radiation types and sources for diverse applications. This technology has been used in multi-layer tubes, aerospace application, and is under investigation in numerous other areas such as structural parts for use as automotive panels, for electro-optical devices, healthcare products, and in many other areas [64]. Regarding the coating industry this technology has been mainly applied in the curing of diverse materials being UV radiation and electron beam the most used radiation sources [65]. 
Radiation curing refers to the process where the energy of UV-light or electron beams is used to induce crosslinking of polymer chains by radical induced mechanism in coatings or in adhesives. This process involves the transformation of a liquid substance into a non-tacky solid within a few seconds [66]. This technique has grown over the last 3 decades and shifted from novelty to a firmly established alternative method for many of the traditionally cured systems [67]. Curing by radiation techniques hold some advantages over traditional methods, mainly attributed to a quick process, the possibility to be carried out at room temperature, no need of solvents and additives (initiators and/or catalysts), the possibility to link the coating to the substrate resulting in more durable coatings, and so on. However, this technique has some disadvantages. For instance, the radiation curing frequently needs inert atmospheres to prevent inhibition of curing, and the high initial cost for the acquisition of the irradiation equipment.

Electron-beam curing has come into extensive use particularly in surface coatings and printings [68]-[71]. Electron beam cured coatings are usually uniformly cured due to the homogenous penetration of the electrons. Such coatings adhere well to a variety of surfaces including metals, wood, textiles, paper, polymers, and glass. Electron beam curing has numerous advantages over conventional thermal curing methods including the ability to combine various materials and functions in a single operation, no substrate heating, low energy consumption, immediate further treatment of converted products without post curing, high efficiency, no emission of organic solvents into the environment, and exact repeatability of process conditions due to a high dose accuracy.

Depending on the applications electron accelerators of different energies may be selected:

1) Low-energy (from $150 \mathrm{keV}$ to $300 \mathrm{keV}$ ): extensively applied for the curing of coatings for paper, wood, CDs, DVDs, metals and polymers, surface grafting for membranes, adhesives for plastics and printing inks, films and multilayer packaging, paints, varnishes, and disinfestations of seeds.

2) Mid-energy (from $300 \mathrm{keV}$ to $5 \mathrm{MeV}$ ): particularly useful for the irradiation of natural polymers, ionexchange membranes for fuel cells application, composite materials, wire and cable insulation, biodegradable blends, and fiber modification.

3) High-energy (from $5 \mathrm{MeV}$ to $10 \mathrm{MeV}$ ): commonly used for the sterilization of medical devices and some pharmaceutical and biological products including the preservation and disinfestations of foods and agricultural products, treatment of lignocelluloses materials to produce ethanol biofuels, removal of organic compounds from wastewater, and decontamination of pesticide packing [72].

Alternatively, gamma radiation has been widely applied for the development of coatings from various materials, especially metals and polymers used as biomaterials. As an example, Jin et al. [73] coated the surface of stainless steel (SS) by grafting 2-hydroxyethylmethacrylate via mutual or simultaneous radiation method under ${ }^{60}$ Co gamma-ray irradiation. Before radiation grafting the surface of SS was modified with dopamine. They demonstrated by water contact angle measurements and platelet adhesion assays that the hydrophilicity and hemocompatibility of the coated SS were improved. On the other hand, Yang et al. [74] grafted acrylamide (AAm) onto titanium metal sheets by using the direct method via gamma irradiation. Results showed that the wettability of the coated titanium surface was greatly improved if compared with the pristine titanium sheet. Also, the hydrophilic coating of polyacrylamide showed good stability because the titanium surface was pretreated using dopamine and presented good adhesive ability.

Coated PP materials have also been prepared by the use of ionizing radiation. An interpenetrating polymer network made of two stimuli-responsive polymers was grafted onto PP films with the aim of developing medicine containing coatings for medical devices. Drug-loaded PP films sustained the delivery of vancomycin, an antimicrobial agent, for several hours and provided release rate values adequate for killing bacteria attempting to adhere to the surface of the PP films [75]. García-Vargas et al. [76] modified separately PP monofilament sutures with glycidyl methacrylate (GMA) and AAc by means of pre-irradiation method using a ${ }^{60} \mathrm{Co}$ source. PPg-AAc sutures exhibited pH-dependent swelling and remarkable high capability to host vancomycin. Some AAc-functionalized sutures were able to inhibit bacterial growth after successive challenges with fresh lawns. These antimicrobial agent-loaded PP sutures could be used as device combo products that minimize the risk of infections.

\section{Biomedical Applications}

\subsection{Smart Polymers}

As above mentioned, smart or stimuli-responsive polymers are high-performance polymers (Figure 2) that 


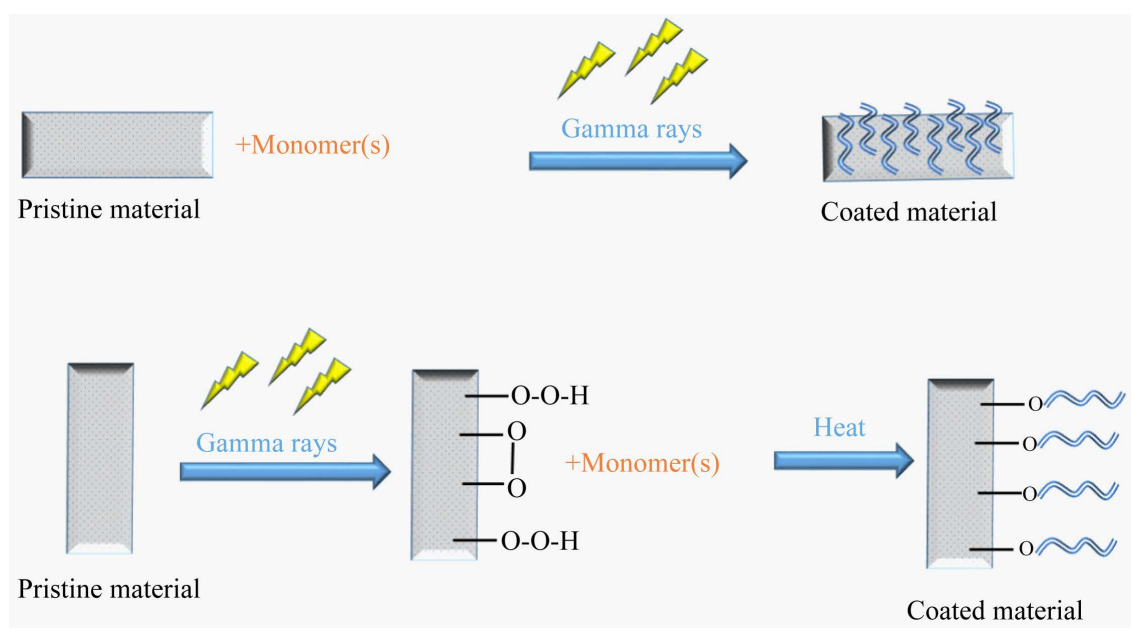

Figure 2. Pristine based thermo-responsive coatings obtained by irradiation grafting for biotechnological purposes.

change their properties when exposed to external stimuli [47] [77]-[82]. In other words, this nomenclature is directly related to their ability to respond to external or internal environmental changes. The most common stimuli correspond to temperature, $\mathrm{pH}$, electromagnetic field and light, where among these, temperature and $\mathrm{pH}$ responsive systems are by far the most important systems concerning biomedical research. Stimuli-responsive polymers have been used in various forms such as graft and block copolymers, hydrogels, polymeric micelles, coatings, and interpenetrating networks [83]-[85].

Temperature-responsive polymers and hydrogels exhibit a volume phase transition at a defined temperature which causes a sudden change in the conformation of the polymeric chains and solvation state as a consequence. The change in temperature is not only relatively easy to control, but also easily applicable to both in vitro and in vivo conditions. Below the LCST, the polymeric chains expand and become hydrophilic and water soluble, while above the LCST the polymeric chains shrink and thus become hydrophobic and water insoluble [47]. LCST and UCST systems are not restricted to aqueous solvent environments. Whatsoever, only the aqueous systems are of interest for biomedical applications. An example of temperature-responsive polymer widely known for a long time is the poly(N-isopropylacrylamide) (PNIPAAm). PNIPAAm dehydrates and its structure collapses at temperatures above its LCST $\left(32^{\circ} \mathrm{C}\right.$ in water), and becomes hydrated and swells at temperatures below its LCST.

On the other hand, the $\mathrm{pH}$ is an important environmental parameter for biomedical applications, taking into account that $\mathrm{pH}$ changes do occur in many specific sites of the human body. The $\mathrm{pH}$-responsive polymers contain ionizable groups that can accept and donate protons in response to an environmental change in $\mathrm{pH}$. Upon ionization the electrostatic repulsions of the generated charges (anions or cations) cause a dramatic extension of coiled chains. The ionization of the pendant acidic or basic groups on polyelectrolytes can be partial due to the electrostatic repulsion from other adjacent ionized groups [47]. By means of swelling properties, in the case of polymers with weakly acidic groups, swelling index increases as the external $\mathrm{pH}$ increases. The opposite is observed if the polymer contains weakly basic groups. Most anionic $\mathrm{pH}$-sensitive polymers used in drug delivery are based on poly(acrylic acid), poly(methacrylic acid), poly(ethylene imine) and poly(l-lysine).

Currently the most prevalent use for smart polymers in biomedicine is specifically related to targeted drug delivery systems [86]-[88]. However, other biomedical applications such as gene and tissue engineering, chemotherapy, biochromatography, and biomembrane technology have also been reported [89]-[93]. The most relevant inconvenient with the use of smart polymers in biomedicine is related to the toxicity or incompatibility of artificial substances with the human body. Nevertheless, stimuli-responsive polymers hold enormous potential in biomedical applications if these obstacles may be overcome.

Ionizing radiation-induced polymerization is an economical, clean, and convenient technique for the synthesis, grafting or modification of biomaterials [94]-[97]. Ionizing radiation (gamma radiation, electron beam or X-ray) allow the creation of interesting polymers with new architectures. Specifically, the use of gamma radiation has some advantages including the possibility to perform grafting at room temperature in solid, liquid or gaseous 
state, no need of additives (catalyst or initiators), high penetrability, much higher grafting yields if compared to electron beam radiation, and surface selectivity by tuning reaction conditions, etc. Burillo et al. [97] prepared a temperature and $\mathrm{pH}$-responsive interpenetrating network by gamma radiation from a ${ }^{60} \mathrm{Co}$ gamma source and electron beam using a Van de Graaff accelerator. Interpenetrating networks of temperature sensitive PNIPAAm and $\mathrm{pH}$ sensitive PAAc were prepared by two consecutive steps. Cross-linking yields were higher for samples irradiated with gamma radiation than those treated with electron beam. The $\mathrm{pH}$ sensitivity from PAAc was conserved while the LCST of PNIPAAm shifted to $28^{\circ} \mathrm{C}$. Ruiz et al. [83] synthesized a smart polymer by grafting an interpenetrating polymer network onto PP films. Three consecutive steps were used: graft copolymerization of PAAc onto PP films by gamma radiation, crosslinking of PP-g-PAAc to form the first network, and synthesis of a second network of PNIPAAm. They found that the interpenetrating network grafted onto PP retained the thermal and $\mathrm{pH}$ sensitivity from PNIPAAm and PAAc respectively. Contreras et al. [98] grafted N, N'-dimethylacrylamide and NIPAAm using pre-irradiation method with gamma-rays. They studied the effect of absorbed dose, monomer concentration and reaction time on the degree of grafting. In addition, grafting of stimuliresponsive polymers onto polymeric matrices of biomedical interest has been reported [99]-[103]. PP films have been modified with temperature-responsive polymers to load nalidixic acid, and non-steroidal anti-inflammatory drugs [103] [104]. Stimuli-responsive bacterial cellulose-g-poly-(acrylic acid) hydrogels were prepared for potential use as oral delivery systems of protein-based drugs using electron beam irradiation [93]. These hydrogels exhibited excellent mucoadhesive potential and cytocompatibility.

\subsection{Smart Coatings}

Conventional and advanced technological applications demand materials with well-defined surface properties. A versatile route employed to provide new properties to certain materials is the surface functionalization. Surface functionalization is the act of modifying the surface of a material by bringing physical, chemical or biological characteristics different from the ones originally found on the surface of a material. A functional surface comprises new and/or modified chemical groups and/or morphological features that determine the interaction with the surrounding environment and subsequently the material properties and behavior [105]-[107].

The surfaces of many materials can be functionalized by applying coatings. Coatings, whether organic, inorganic or hybrid, are a class of materials that may be applied to the surface of certain materials in order to decorate or modify it. Coatings may partially or completely cover the surface of materials and in addition, they may be tailored for many applications in which they should be able to perform well-defined variety of functions. Coatings do change the surface properties of the substrate such as wettability, adhesion, corrosion or wear resistance, and so on. There are innumerous functional coatings present in our daily life including laptops, paints, lacquers, solar panels, home furniture, cars and even in more advanced applications or systems such as invisible paints, medical devices, or orthopedic implants. A major consideration for most coating processes is that the coating must be applied at a controlled thickness. The thickness of the coating system and the number of layers depends on the final application of the coated material ranging from a few up to several hundreds of micrometers. Generally, each layer is aimed for specific functionalities that include adhesion to the bare metal or adhesion between different layers, corrosion inhibition, anti-fouling, water repellence, and wear resistance, among others [108]-[112].

The concept of "smart", "intelligent" or stimuli-responsive coatings is relatively recent and has been applied to functional coatings that change their properties in response to environmental stimulus. Smart coatings cover a wide-range of characteristics but the main performance is related to durability. However, concerning industrial coatings, energy consumption of the processes is the most urgent current focus. The applicability of reactive smart coatings to various substrates, like polymers, metals, or composites, generates a fairly universal platform without relying on the broad chemical alteration of the bulk material. As a consequence, this minimizes contaminations and promotes a biocompatible process free of harmful solvents, initiators, or catalysts. Therefore, smart coatings compose a class of materials with enormous technological interest. Intelligent coatings have been commonly used for various applications, including but not limited to the biomedical ones [113]-[115]. Depending upon the applications traditional functional coatings exhibit significantly different physicochemical properties. Polymer-based smart coatings are expected to undergo a reversible phase transition which causes changes in polymer conformation and polymer surface energy. Responses to mechanical deformations, temperature, $\mathrm{pH}$, ionic strength, electric and magnetic fields, surface and interfacial phenomena, and the development of nano- 
structures are the most common targets when designing coating polymeric films [116] [117]. However, the external stimuli-temperature, $\mathrm{pH}$ or ionic strength of solvent, light or electromagnetic fields—often require finetuning of surface properties. Coatings in biomedical engineering have emerged as an important topic and play a critical role in biological applications [118]. Coating strategies target the spatially-controlled design of interfaces as well as the development of smart surfaces. In addition, in order to truly mimic a biological interface, biomaterials must not only provide excellent control over the distribution and orientation of biomolecules, but they may also overcome the intrinsic static character of pristine materials. A promising route towards this goal is based on the coating of biomaterials using stimuli-responsive polymers [119]-[121]. These intelligent coatings will provide a dynamic control of material properties to direct, for example, cell or biomolecule adhesion, cell detachment, controlled drug delivery, antimicrobial properties, etc.

Materials can be modified with smart coatings by grafting polymers with reactive end groups and architectures onto their surface. One strategy is the use of radiation techniques such as gamma radiation and electron beam which have proved to be useful in the development of coatings for materials with biomedical use in regenerative medicine and controlled drug delivery [75] [76] [82] [86] [100]-[104] [122]-[124].

Polycaprolactone, a compound frequently used as the base polymer in scaffolds engineered towards tissue engineering applications was modified with $\mathrm{pH}$-responsive PAAc by means of gamma radiation [124]. The introduced - $\mathrm{COOH}$ groups could permit the subsequent attachment of biomolecules and thus making them useful templates for tissue engineering applications. On the other hand, stable coatings of temperature-responsive poly(vinyl methyl ether) have been immobilized onto polystyrene surfaces by low energy electron beam irradiation [125]. Based-polymer coatings have been used to coat biomaterials for their use in drug-eluting medical devices with anti-fouling properties. Chitosan and chitosan hydrogels were immobilized on high density polyethylene tubes previously modified with AAc by electron beam irradiation [126]. The chitosan hydrogel layers were further modified with heparin to improve antibacterial and blood compatibility properties. On the other hand, silicone rubber (SR) has been modified using gamma rays, with some stimuli-responsive polymers to improve its ability to host either antimicrobial or anti-inflammatory drugs [38] [127] [128]. The grafting of these polymers has improved the performance of SR for biomedical applications. Commercial polyurethane catheters (Tecof$l x^{\circledR}$, TFX) were irradiated with gamma rays and then coated with stimuli-responsive polymers to obtain vancomycin-eluting implantable medical devices [129]. Authors found that TFX-based insertable medical devices were able to inhibit the growth of $S$. aureus acting as a drug delivery system. In addition, cotton gauzes have been coated via one-step grafting (direct method) using ${ }^{60} \mathrm{Co}$ gamma-rays with the thermo-pH sensitive 2-(dimethylamino)ethyl methacrylate (DMAEMA) [130]. DMAEMA grafting makes gauzes more hydrophilic with enhanced blood absorption capability and favored collagenase activity. Cotton-g-DMAEMA gauzes were subsequently quaternized with methyl iodide in order to make them less prone to be colonized by bacteria (Figure 3).

\section{Conclusions and Future Prospects}

Ionizing radiation stands as an important and efficient technique to modify biomaterials with stimuli-responsive coatings and/or stimuli-responsive monomers/functional groups. In addition to conventional methods, the use of irradiation based techniques allows the development of covalent-linked coatings which are desirable for many applications, including biomedical, automotive, textile and biotechnological industry among others.

From a development point of view the design and the appropriate coating properties should be defined by the applications in which these materials are intended for. On this account, the irradiation source and method, as well as polymer and monomer selection should be based on this premise. On the other hand, from a general perspective the combination of stimuli-responsive coatings and biomaterials led to emerging technology platforms suitable for the development of advanced materials able to mimic biological systems as well as respond to biological changes, such as $\mathrm{pH}$ or temperature variations.

Future developments of this technology promise to greatly improve the performance of biomaterials concerning specific biomedical and biotechnological applications including drug-eluting medical devices, anti-fouling biomedical devices and tissue engineering.

Novel and recent approaches in this particular field have been delivered over the last decades by several scientists which include the radiation grafting inside the nanopores of polymeric matrices. This technique may not exclusively hold the ability to confer distinct responsive properties to materials but assure localized changes 


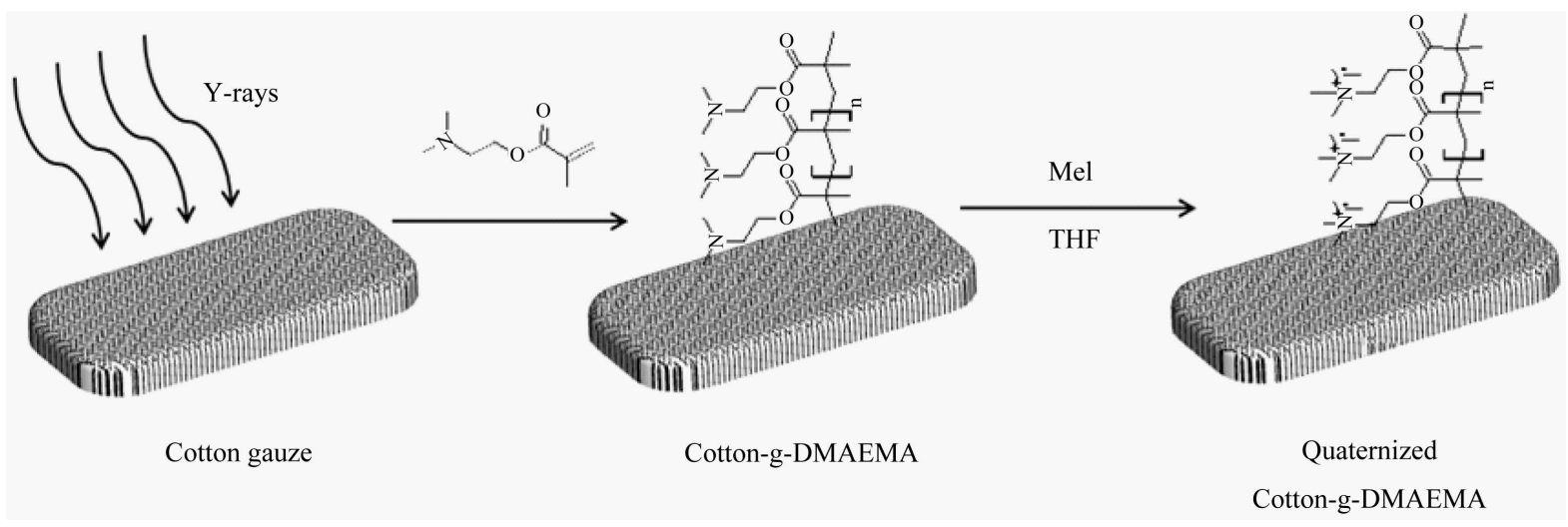

Figure 3. Schematic representation of the cotton-g-DMAEMA synthesis and subsequent quaternization with methyl iodide.

in the nano/microstructure of the systems and thus contribute to great and novel perspectives in a near future.

\section{Acknowledgements}

H.I. Melendez-Ortiz is grateful to the program Cátedras-CONACyT (Mexico). This chapter was supported by DGAPA-UNAM Grant IN200714, CONACYT-CNPq Project 174378 (Mexico) and CNPq project number 490200/2011-7 (Brazil). The authors would like to acknowledge M.L. Escamilla, M. Cruz, and E. Palacios from ICN-UNAM and B. Puente from CIQA for technical assistance.

\section{References}

[1] Hoffman, A.S. (2013) Stimuli-Responsive Polymers: Biomedical Applications and Challenges for Clinical Translation. Advanced Drug Delivery Reviews, 65, 10-16. http://dx.doi.org/10.1016/j.addr.2012.11.004

[2] Peppas, N.A., Hilt, J.Z., Khademhosseini, A., et al. (2006) Hydrogels in Biology and Medicine: From Molecular Principles to Bionanotechnology. Advanced Materials, 18, 1345-1360. http://dx.doi.org/10.1002/adma.200501612

[3] Zhou L., Yuan W., Yuan J., et al. (2008) Preparation of Double-Responsive $\mathrm{SiO}_{2}$-g-DMAEMA Nanoparticles via ATRP. Materials Letters 62, 1372-1375. http://dx.doi.org/10.1016/j.matlet.2007.08.057

[4] Medeirosa, S.F., Santos, A.M. and Fessi, H. (2011) Stimuli-Responsive Magnetic Particles for Biomedical Applications. International Journal of Pharmaceutics 403, 139-161. http://dx.doi.org/10.1016/j.ijpharm.2010.10.011

[5] Klouda, L. and Mikos, A.G. (2008) Thermoresponsive Hydrogels in Biomedical Applications. European Journal of Pharmaceutics and Biopharmaceutics, 68, 34-45. http://dx.doi.org/10.1016/j.ejpb.2007.02.025

[6] Ulbricht, M., Özdemir, S. and Geismann, C. (2006) Functionalized Track-Etched Membranes as Versatile Tool to Investigate Stimuli-Responsive Polymers for “Smart” Nano- and Microsystems. Desalination, 199, 150-152. http://dx.doi.org/10.1016/j.desal.2006.03.159

[7] Adem, E., Avalos-Borja, M., Bucio, E., Burillo, G., Castillon, F.F. and Cota, L. (2005) Surface Characterization of Binary Grafting of AAc/NIPAAm onto Poly(tetrafluoroethylene) (PTFE). Nuclear Instruments and Methods in Physics Research Section B, 234, 471-476. http://dx.doi.org/10.1016/j.nimb.2005.02.009

[8] Yang, J.M. and Lin, H.T. (2004) Properties of Chitosan Containing PP-g-AA-g-NIPAAm of NIPAAm/ $\beta$-CD-g-PP Bigraft Nonwoven Fabric for Wound Dressing. Journal of Membrane Science, 243, 1-7. http://dx.doi.org/10.1016/j.memsci.2004.03.019

[9] Montemor, M.F. (2014) Functional and Smart Coatings for Corrosion Protection: A Review of Recent Advances. Surface and Coatings Technology, 258, 17-37. http://dx.doi.org/10.1016/j.surfcoat.2014.06.031

[10] El-Mohdy, H.L. and Safrany, A. (2008) Preparation of Fast Response Superabsorbent Hydrogels by Radiation Polymerization and Crosslinking of N-Isopropylacrylamide in Solution. Radiation Physics and Chemistry, 77, $273-279$. http://dx.doi.org/10.1016/j.radphyschem.2007.05.006

[11] Ebara, M., Hoffman, J.M., Stayton, P.S. and Hoffman, A.S. (1999) Surface Modification of Microfluidic Channels by UVMediated Graft Polymerization of Non-Fouling and “Smart” Polymers. Radiation Physics and Chemistry, 76, 14091413. http://dx.doi.org/10.1016/j.radphyschem.2007.02.072

[12] Uhlmann, P., Ionov, L., Houbenov, N., Nitschke, M., Grundke, K., Motornov, M., et al. (2006) Surface Functionalization by Smart Coatings: Stimuli-Responsive Binary Polymer Brushes. Progress in Organic Coatings, 55, 168-174. 
http://dx.doi.org/10.1016/j.porgcoat.2005.09.014

[13] Honey, P.J., Rijo, J., Anju, A. and Anoop, K.R. (2014) Smart Polymers for the Controlled Delivery of Drugs—A Concise Overview. Acta Pharmaceutica Sinica B, 4, 120-127. http://dx.doi.org/10.1016/j.apsb.2014.02.005

[14] Zhang, K. and Wu, X.Y. (2004) Temperature and pH-Responsive Polymeric Composite Membranes for Controlled Delivery of Proteins and Peptides. Biomaterials, 25, 5281-5291. http://dx.doi.org/10.1016/j.biomaterials.2003.12.032

[15] Gotowska, A., Bark, J.S., Kwon, I.C., Bae, Y.H., Cha, Y. and Kim, S.W. (1997) Squeezing Hydrogels for Controlled Oral Drug Delivery. Journal of Controlled Release, 48, 141-148. http://dx.doi.org/10.1016/S0168-3659(97)00041-2

[16] Sebenik, A. (1998) Living Free-Radical Block Copolymerization Using Thio-Iniferters. Progress in Polymer Science, 23, 875-917. http://dx.doi.org/10.1016/S0079-6700(98)00001-X

[17] Moad, G. and Solomon, D.H. (2006) The Chemistry of Radical Polymerization. Second Edition, Elsevier, Oxford.

[18] Rizzardo, E., Chiefari, J., Chong, B.Y.K., Ercole, F., Krstina, J., Jeffery, J., et al. (1999) Tailored Polymers by Free Radical Processes. Macromolecular Symposia, 143, 291-307. http://dx.doi.org/10.1002/masy.19991430122

[19] Moad, G., Rizzardo, E. and Thang, S.H. (2005) Living Radical Polymerization by the RAFT Process. Australian Journal of Chemistry, 58, 379-410. http://dx.doi.org/10.1071/CH05072

[20] Chapiro, A. (1962) Radiation Chemistry of Polymeric Systems. Interscience Publishers, New York.

[21] Chapiro, A. (1977) Radiation Induced Grafting. Radiation Physics and Chemistry, 9, 55-67. http://dx.doi.org/10.1016/0146-5724(77)90072-3

[22] Dennis, G.R., Garnett, J.L. and Zilic, E. (2003) Cure Grafting-A Complementary Technique to Preirradiation and Simultaneous Processes? Radiation Physics and Chemistry, 67, 391-395. http://dx.doi.org/10.1016/S0969-806X(03)00073-2

[23] Kimura, Y., Asano, M., Chen, J.H., Maekawa, Y., Katakai, R. and Yoshida, M. (2008) Influence of Grafting Solvents on the Properties of Polymer Electrolyte Membranes Prepared by $\gamma$-Ray Preirradiation Method. Radiation Physics and Chemistry, 77, 864-870. http://dx.doi.org/10.1016/j.radphyschem.2007.12.012

[24] Clough, R.L. (2001) High-Energy Radiation and Polymers: A Review of Commercial Processes and Emerging Applications. Nuclear Instruments and Methods in Physics Research Section B, 185, 8-33. http://dx.doi.org/10.1016/S0168-583X(01)00966-1

[25] Gupta, B., Anjum, N., Jain, R., Revagade, N. and Singh, H. (2004) Development of Membranes by Radiation-Induced Graft Polymerization of Monomers onto Polyethylene Films. Journal of Macromolecular Science, Part C: Polymer Reviews, 44, 275-309. http://dx.doi.org/10.1081/mc-200029334

[26] Odian, G., Sobel, M., Rossi, A. and Klein, R. (1961) Radiation-Induced Graft Polymerization: The Trommsdorff Effect of Methanol. Journal of Polymer Science, 55, 663-673. http://dx.doi.org/10.1002/pol.1961.1205516220

[27] Mazzei, R., García, G., Massa, G. and Filevich, A. (2007) Grafting of Polypropylene and Poly(vinylidene fluoride) Films Implanted with $\mathrm{Ar}^{+}$Ions. Nuclear Instruments and Methods in Physics Research Section B, 255, 314-320. http://dx.doi.org/10.1016/j.nimb.2006.11.122

[28] Ramírez-Fuentes, Y.S., Bucio, E. and Burillo, G. (2007) Radiation-Induced Grafting of Stimuli-Responsive Binary Monomers onto Polypropylene Films. Nuclear Instruments and Methods in Physics Research Section B, 265, 183-186. http://dx.doi.org/10.1016/j.nimb.2007.08.046

[29] Bucio, E., Cedillo, G., Burillo, G. and Ogawa, T. (2001) Radiation-Induced Grafting of Functional Acrylic Monomers onto Polyethylene and Polypropylene Films Using Acryloyl Chloride. Polymer Bulletin, 46, 115-121. http://dx.doi.org/10.1007/s002890170096

[30] Alvarez-Lorenzo, C., Bucio, E., Burillo, G. and Concheiro, A. (2010) Medical Devices Modified at the Surface by $\gamma$-Ray Grafting for Drug Loading and Delivery. Expert Opinion on Drug Delivery, 7, 173-185. http://dx.doi.org/10.1517/17425240903483174

[31] Li, J., Sato, K., Ichiduri, S., Asano, S., Ikeda, S., Iida, M., et al. (2004) Pre-Irradiation Induced Grafting of Styrene into Crosslinked and Non-Crosslinked Polytetrafluoroethylene Films for Polymer Electrolyte Fuel Cell Applications. I: Influence of Styrene Grafting Conditions. European Polymer Journal, 40, 775-783. http://dx.doi.org/10.1016/j.eurpolymj.2003.11.018

[32] Kamel, I., Machi, S. and Silverman, J.J. (1972) Radiation-Induced Grafting of Styrene Vapor to Polyethylene. Journal of Polymer Science Part A-1: Polymer Chemistry, 10, 1019-1029. http://dx.doi.org/10.1002/pol.1972.150100407

[33] Ratner, D. and Hoffman, A.S. (1974) The Effect of Cupric Ion on the Radiation Grafting of $N$-vinyl-2-pyrrolidone and Other Hydrophilic Monomers onto Silicone Rubber. Journal of Applied Polymer Science, 18, 3183-3204. http://dx.doi.org/10.1002/app.1974.070181101

[34] Barsbay, M. and Güven, O. (2009) A Short Review of Radiation-Induced Raft-Mediated Graft Copolymerization: A 
Powerful Combination for Modifying the Surface Properties of Polymers in a Controlled Manner. Radiation Physics and Chemistry, 78, 1054-1059. http://dx.doi.org/10.1016/j.radphyschem.2009.06.022

[35] Chiefari, J., Chong, Y.K., Ercole, F., Krstina, J., Jeffery, J., Le, T.P.T., et al. (1998) Living Free-Radical Polymerization by Reversible Addition-Fragmentation Chain Transfer: The RAFT Process. Macromolecules, 31, 5559-5562. http://dx.doi.org/10.1021/ma9804951

[36] Barner, L., Quinn, J.F., Barner-Kowollik, C., Vana, P. and Davis, T.P. (2003) Reversible Addition-Fragmentation Chain Transfer Polymerization Initiated with $\gamma$-Radiation at Ambient Temperature: An Overview. European Polymer Journal, 39, 449-459. http://dx.doi.org/10.1016/S0014-3057(02)00247-1

[37] Bucio, E., Burillo, G., Adem, E. and Coqueret, X. (2005) Temperature Sensitive Behavior of Poly( $N$-isopropylacrylamide) Grafted onto EB-Irradiated Polypropylene. Macromolecular Materials and Engineering, 290, 745-752. http://dx.doi.org/10.1002/mame.200500074

[38] Burillo, G., Díaz, A. and Bucio, E. (2006) Characterization of Thermo and pH Sensitivity of Binary Graft Copolymers onto Polytetrafluoroethylene. Journal of the Mexican Chemical Society, 50, 1-4.

[39] Kang, Y.L. and Neoh, K.G. (2002) Synthesis and Characterization of Poly( $N$-isopropylacrylamide)-Graft-Poly(vinylidene fluoride) Copolymers and Temperature-Sensitive Membranes. Langmuir, 18, 6416-6423. http://dx.doi.org/10.1021/la020241f

[40] Pu, H., Ding, Z. and Ma, Z. (1996) Preparation, Characterization, and Properties of EVA Preirradiation Grafted NIPAAm. Journal of Applied Polymer Science, 10, 1529-1535. http://dx.doi.org/10.1002/(SICI)1097-4628(19961205)62:10<1529::AID-APP5>3.0.CO;2-Q

[41] Burillo, G., Bucio, E., Arenas, E. and Lopez, G.P. (2007) Temperature and pH Sensitive Swelling Behavior of Binary DMAEMA/4VP Grafts on Polypropylene Films. Macromolecular Materials and Engineering, 292, 214-219. http://dx.doi.org/10.1002/mame.200600394

[42] Ferraz, C.C., Varca, G.H.C., Ruiz, J.C., Lopes, P.S., Mahtor, M.B. and Lugão, A.B. (2014) Radiation-Grafting of Thermo- and pH-Responsive Poly(N-vinylcaprolactam-co-acrylic acid) onto Silicone Rubber and Polypropylene Films for Biomedical Purposes. Radiation Physics and Chemistry, 97, 298-303. http://dx.doi.org/10.1016/j.radphyschem.2013.12.027

[43] Yan, L., Zhu, Q. and Kenkare, P.U. (2000) Lower Critical Solution Temperature of Linear PNIPA Obtained from a Yukawa Potential of Polymer Chains. Journal of Applied Polymer Science, 78, 1971-1976. http://dx.doi.org/10.1002/1097-4628(20001209)78:11<1971::AID-APP170>3.0.CO;2-P

[44] Feil, H., Bae, Y.H., Feijen, J. and Kim, S.W. (1993) Effect of Comonomer Hydrophilicity and Ionization on the Lower Critical Solution Temperature of $N$-Isopropylacrylamide Copolymers. Macromolecules, 26, 2496-2500. http://dx.doi.org/10.1021/ma00062a016

[45] Heskins, M. and Guillet, J.E. (1969) Solution Properties of Poly( -isopropylacrylamide). Journal of Macromolecular Science, 2, 1441-1455. http://dx.doi.org/10.1080/10601326808051910

[46] Grinberg, A., Grosberg, Y. and Tanaka, T. (2000) Studies of the Thermal Volume Transition of Poly( $N$-isopropylacrylamide) Hydrogels by High-Sensitivity Differential Scanning Microcalorimetry. 2. Thermodynamic Functions. Macromolecules, 33, 8685-8692. http://dx.doi.org/10.1021/ma000527w

[47] Gil, E.S. and Hudson, S.M. (2004) Stimuli-Responsive Polymers and Their Bioconjugates. Progress in Polymer Science, 29, 1173-1222. http://dx.doi.org/10.1016/j.progpolymsci.2004.08.003

[48] Siegel, R.A. (1993) Hydrophobic Weak Polyelectrolyte Gels: Studies of Swelling Equilibria and Kinetics. Advances in Polymer Science, 109, 233-267. http://dx.doi.org/10.1007/3-540-56791-7_6

[49] Tonge, S.R. and Tighe, B.J. (2001) Responsive Hydrophobically Associating Polymers: A Review of Structure and Properties. Advanced Drug Delivery Reviews, 53, 109-122. http://dx.doi.org/10.1016/S0169-409X(01)00223-X

[50] Stubbs, M., McSheehy, P.M.J. and Griffiths, J.R. (1999) Causes and Consequences of Acidic pH in Tumors: A Magnetic Resonance Study. Advances in Enzyme Regulation, 39, 13-30. http://dx.doi.org/10.1016/S0065-2571(98)00018-1

[51] Katz, J.S. and Burdick, J.A. (2010) Light-Responsive Biomaterials: Development and Applications. Macromolecular Bioscience, 10, 339-348. http://dx.doi.org/10.1002/mabi.200900297

[52] Lin, L., Yan, Z., Gu, J.S., Zhang, Y.Y., Feng, Z. and Yu, Y.L. (2009) UV-Responsive Behavior of AzopyridineContaining Diblock Copolymeric Vesicles: Photoinduced Fusion, Disintegration and Rearrangement. Macromolecular Rapid Communications, 30, 1089-1093. http://dx.doi.org/10.1002/marc.200900105

[53] Oh, Y.J., Nam, J.A., Al-Nahain, A., Lee, S., In, I. and Park, S.Y. (2012) Spiropyran-Conjugated Pluronic as a Dual Responsive Colorimetric Detector. Macromolecular Rapid Communications, 33, 1958-1963. http://dx.doi.org/10.1002/marc.201200416

[54] Eastoe, J., Dominguez, M.S., Wyatt, P., Beeby, A. and Heenan, R.K. (2002) Properties of a Stilbene-Containing Gemi- 
ni Photosurfactant: Light-Triggered Changes in Surface Tension and Aggregation. Langmuir, 18, 7837-7844. http://dx.doi.org/10.1021/la0257384

[55] James, H.P., John, R., Alex, A. and Anoop, K.R. (2014) Smart Polymers for the Controlled Delivery of Drugs-A Concise Overview. Acta Pharmaceutica Sinica B, 4, 120-127. http://dx.doi.org/10.1016/j.apsb.2014.02.005

[56] Yager, K.G. and Barrett, C.J. (2009) Azobenzene Polymers for Photonic Applications. In: Zhao, Y. and Ikeda, T., Eds., Smart Light-Responsive Materials: Azobenzene-Containing Polymers and Liquid Crystals, John Wiley \& Sons, Inc., Hoboken. http://dx.doi.org/10.1002/9780470439098.ch1

[57] Andrade, A., Ferreira, R., Fabris, J. and Domingues, R. (2011) Coating Nanomagnetic Particles for Biomedical Applications. In: Fazel-Rezai, R., Ed., Biomedical Engineering-Frontiers and Challenges, InTech, Rijeka. http://dx.doi.org/10.5772/19519

[58] Chen, J. and Chang, C. (2014) Fabrications and Applications of Stimulus-Responsive Polymer Films and Patterns on Surfaces: A Review. Materials, 7, 805-875. http://dx.doi.org/10.3390/ma7020805

[59] Cuevas, J.M., Alonso, J., German, L., Iturrondobeitia, M., Laza, J.M., Vilas, J.L. and León, L.M. (2009) Magneto-Active Shape Memory Composites by Incorporating Ferromagnetic Microparticles in a Thermo-Responsive Polyalkenamer. Smart Materials and Structures, 18, Article ID: 075003.

[60] Zhang, D.W., Liu, Y.J. and Leng, J.S. (2010) Study on the Activation of Styrene-Based Shape Memory Polymer by Medium-Infrared Laser Light. Applied Physics Letters, 96, Article ID: 111905.

[61] Abedini, A., Daud, A.R. and Hamid, M.A.A. (2014) Radiolytic Formation of $\mathrm{Fe}_{3} \mathrm{O}_{4}$ Nanoparticles: Influence of Radiation Dose on Structure and Magnetic Properties. PLOS ONE, 9, e90055. http://dx.doi.org/10.1371/journal.pone.0090055

[62] Turcu, R., Nan, A., Craciunescu, I., Pana, O., Leostean, C. and Macavei, S. (2009) Smart Composites Based on Magnetic Nanoparticles and Responsive Polymers. Journal of Physics, 182, Article ID: 012081. http://dx.doi.org/10.1088/1742-6596/182/1/012081

[63] Kharissova, O.V., Kharisov, B.I. and Mendez, U.O. (2012) Radiation-Assisted Synthesis of Composites, Materials, Compounds, and Nanostructures. Wiley Encyclopedia of Composites, 1-26. http://dx.doi.org/10.1002/9781118097298.weoc212

[64] Parejo Calvo, W.A., Duarte, C.L., Machado, L.D.B., Manzoli, J.E., Geraldo, A.B.C., Kodama, Y., et al. (2012) Electron Beam Accelerators Trends in Radiation Processing Technology for Industrial and Environmental Applications in Latin America and the Caribbean. Radiation Physics and Chemistry, 81, 1276-1281. http://dx.doi.org/10.1016/j.radphyschem.2012.02.013

[65] Salleh, N.G.N., Yhaya, M.F., Hassan, A., Bakar, A.A. and Mokhtar, M. (2011) Effect of UV/EB Radiation Dosages on the Properties of Nanocomposite Coatings. Radiation Physics and Chemistry, 80, 136-141. http://dx.doi.org/10.1016/j.radphyschem.2010.07.021

[66] Bajpai, M., Shukla, V. and Kumar, A. (2002) Film Performance and UV Curing of Epoxy Acrylate Resins. Progress in Organic Coatings, 44, 271-278. http://dx.doi.org/10.1016/S0300-9440(02)00059-0

[67] Webster, G. (1997) UV and EB Curing Technology and Equipment. Wiley/SITA, Oxford.

[68] Sohn, J.Y., Gwon, S.J., Choi, J.H., Shin, J. and Nho, Y.C. (2008) Preparation of Polymer-Coated Separators Using an Electron Beam Irradiation. Nuclear Instruments and Methods in Physics Research Section B, 266, 4994-5000. http://dx.doi.org/10.1016/j.nimb.2008.09.002

[69] Youssef, H.A., Ali, Z.I. and Zahran, A.H. (2001) Electron Beam Structure Modification of Poly(vinyl chloride)-Wire Coating. Polymer Degradation and Stability, 74, 213-218. http://dx.doi.org/10.1016/S0141-3910(01)00062-3

[70] Salleh, N.G., Glasel, H.J. and Mehnert, R. (2002) Development of Hard Materials by Radiation Curing Technology. Radiation Physics and Chemistry, 63, 475-479. http://dx.doi.org/10.1016/S0969-806X(01)00542-4

[71] Ruiz, C.S.B., Machado, L.D.B., Pino, E.S. and Sampa, M.H.O. (2002) Characterization of a Clear Coating Cured by UV/EB Radiation. Radiation Physics and Chemistry, 63, 481-483. http://dx.doi.org/10.1016/S0969-806X(01)00592-8

[72] Chmielewski, A.G., Al-Sheikhly, M., Berejka, A.J., Cleland, M.R. and Antoniak, M. (2014) Recent Developments in the Application of Electron Accelerators for Polymer Processing. Radiation Physics and Chemistry, 94, 147-150. http://dx.doi.org/10.1016/j.radphyschem.2013.06.024

[73] Jin, W., Yang, L., Yang, W., Chen, B. and Chen, J. (2014) Grafting of HEMA onto Dopamine Coated Stainless Steel by ${ }^{60} \mathrm{Co}-\gamma$ Irradiation Method. Radiation Physics and Chemistry, 105, 57-62. http://dx.doi.org/10.1016/j.radphyschem.2014.06.018

[74] Yang, W., Yang, L., Shi, Y., Chen, B. and Chen, J. (2013) Radiation Grafting of Acrylamide onto Surface of Dopamine Functionalised Titanium. Surface Engineering, 29, 667-670. http://dx.doi.org/10.1179/1743294413Y.0000000186 
[75] Muñoz-Muñoz, F., Ruiz, J.C., Alvarez-Lorenzo, C., Concheiro, A. and Bucio, E. (2009) Novel Interpenetrating Smart Polymer Networks Grafted onto Polypropylene by Gamma Radiation for Loading and Delivery of Vancomycin. European Polymer Journal, 45, 1859-1867. http://dx.doi.org/10.1016/j.eurpolymj.2009.04.023

[76] García-Vargas, M., González-Chomón, C., Magariños, B., Concheiro, A., Alvarez-Lorenzo, C. and Bucio, E. (2014) Acrylic Polymer-Grafted Polypropylene Sutures for Covalent Immobilization or Reversible Adsorption of Vancomycin. International Journal of Pharmaceutics, 461, 286-295. http://dx.doi.org/10.1016/j.ijpharm.2013.11.060

[77] Cabane, E., Zhang, X., Langowska, K., Palivan, C.G. and Meier, W. (2012) Stimuli-Responsive Polymers and Their Applications in Nanomedicine. Biointerphases, 7, 1-27. http://dx.doi.org/10.1007/s13758-011-0009-3

[78] Stuart, M.A.C., Huck, W.T.S., Genzer, J., Müller, M., Ober, C., Stamm, M., et al. (2010) Emerging Applications of Stimuli-Responsive Polymer Materials. Nature Materials, 9, 101-113. http://dx.doi.org/10.1038/nmat2614

[79] Chen, J.K. and Chang, C.J. (2014) Fabrications and Applications of Stimulus-Responsive Polymer Films and Patterns on Surfaces: A Review. Materials, 7, 805-875. http://dx.doi.org/10.3390/ma7020805

[80] Meléndez-Ortiz, H.I. and Bucio, E. (2009) Stimuli-Sensitive Behaviour of Binary Graft Co-Polymers (PP-g-DMAEMA)g-NIPAAm and (PP-g-4VP)-g-NIPAAm in Acidic and Basic Medium. Designed Monomers \& Polymers, 12, 99-108. http://dx.doi.org/10.1163/156855508X391167

[81] Zhang, Q., Koa, N.R. and Oh, J.K. (2012) Recent Advances in Stimuli-Responsive Degradable Block Copolymer Micelles: Synthesis and Controlled Drug Delivery Applications. Chemical Communications, 48, 7542-7552. http://dx.doi.org/10.1039/c2cc32408c

[82] Hu, J., Zhang, G., Ge, Z. and Liu, S. (2014) Stimuli-Responsive Tertiary Amine Methacrylate-Based Block Copolymers: Synthesis, Supramolecular Self-Assembly and Functional Applications. Progress in Polymer Science, 39, 10961143. http://dx.doi.org/10.1016/j.progpolymsci.2013.10.006

[83] Ruiz, J.C., Burillo, G. and Bucio, E. (2007) Interpenetrating Thermo and pH Stimuli-Responsive Polymer Networks of PAAc/PNIPAAm Grafted onto PP. Macromolecular Materials and Engineering, 292, 1176-1188. http://dx.doi.org/10.1002/mame.200700178

[84] Liu, X., Guo, H. and Zha, L. (2012) Study of pH/Temperature Dual Stimuli-Responsive Nanogels with Interpenetrating Polymer Network Structure. Polymer International, 61, 1144-1150. http://dx.doi.org/10.1002/pi.4192

[85] Cheng, W., Gu, L., Ren, W. and Liu, Y. (2014) Stimuli-Responsive Polymers for Anti-Cancer Drug Delivery. Materials Science and Engineering: C, 45, 600-608. http://dx.doi.org/10.1016/j.msec.2014.05.050

[86] Lee, S.M. and Nguyen, S.B.T. (2013) Smart Nanoscale Drug Delivery Platforms from Stimuli-Responsive Polymers and Liposomes. Macromolecules, 46, 9169-9180. http://dx.doi.org/10.1021/ma401529w

[87] Mura, S., Nicolas, J. and Couvreur, P. (2013) Stimuli-Responsive Nanocarriers for Drug Delivery. Nature Materials, 12, 991-1003. http://dx.doi.org/10.1038/nmat3776

[88] Ward, M.A. and Georgiou, T.K. (2011) Thermoresponsive Polymers for Biomedical Applications. Polymers, 3, 12151242. http://dx.doi.org/10.3390/polym3031215

[89] Terefe, N.S., Glagovskaia, O., De Silva, K. and Stockmann, R. (2014) Application of Stimuli Responsive Polymers for Sustainable Ion Exchange Chromatography. Food and Bioproducts Processing, 92, 208-225. http://dx.doi.org/10.1016/j.fbp.2014.02.003

[90] Ayano, E. and Kanazawa, H. (2006) Aqueous Chromatography System Using Temperature-Responsive PolymerModified Stationary Phases. Journal of Separation Science, 29, 738-749. http://dx.doi.org/10.1002/jssc.200500485

[91] Cai, T., Li, M., Neohab, K.G. and Kang, E.T. (2012) Preparation of Stimuli Responsive Polycaprolactone Membranes of Controllable Porous Morphology via Combined Atom Transfer Radical Polymerization, Ring-Opening Polymerization and Thiol-Yne Click Chemistry. Journal of Materials Chemistry, 22, 16248-16258. http://dx.doi.org/10.1039/c2jm33419d

[92] Chu, L.Y., Xie, R. and Ju, X.J. (2011) Stimuli-Responsive Membranes: Smart Tools for Controllable Mass-Transfer and Separation Processes. Chinese Journal of Chemical Engineering, 19, 891-903. http://dx.doi.org/10.1016/S1004-9541(11)60070-0

[93] Ahmad, N., Amin, M.C.I.M., Mahali, S.M., Ismail, I. and Chuang, V.T.G. (2014) Biocompatible and Mucoadhesive Bacterial Cellulose- $g$-Poly(acrylic acid) Hydrogels for Oral Protein Delivery. Molecular Pharmaceutics, 11, 41304142. http://dx.doi.org/10.1021/mp5003015

[94] El-Mohdy, H.L.A. (2013) Thermo-Responsive Behavior of Radiation-Induced Poly( $N$-isopropylacrylamide)/Polyethylene Oxide Nanocomposite. Journal of Polymer Research, 20, 206. http://dx.doi.org/10.1007/s10965-013-0206-5 http://link.springer.com/article/10.1007\%2Fs10965-013-0206-5

[95] Meléndez-Ortiz, H.I. and Bucio, E. (2008) Radiation Synthesis of a Thermo-pH Responsive Binary Graft Copolymer (PP-g-DMAEMA)-g-NIPAAm by a Two Step Method. Polymer Bulletin, 61, 619-629. 
http://dx.doi.org/10.1007/s00289-008-0982-y

[96] Meléndez-Ortiz, H.I., Bucio, E. and Burillo, G. (2009) Radiation-Grafting of 4-Vinylpyridine and N-Isopropylacrylamide onto Polypropylene to Give Novel pH and Thermo-Sensitive Films. Radiation Physics and Chemistry, 78, 1-7. http://dx.doi.org/10.1016/j.radphyschem.2008.08.003

[97] Burillo, G., Briones, M. and Adem, E. (2007) IPN’s of Acrylic Acid and N-Isopropylacrylamide by Gamma and Electron Beam Irradiation. Nuclear Instruments and Methods in Physics Research Section B, 265, 104-108. http://dx.doi.org/10.1016/j.nimb.2007.08.033

[98] Contreras-García, A., Burillo, G., Aliev, R. and Bucio, E. (2008) Radiation Grafting of N,N’-Dimethylacrylamide and $N$-Isopropylacrylamide onto Polypropylene Films by Two-Step Method. Radiation Physics and Chemistry, 77, 936940. http://dx.doi.org/10.1016/j.radphyschem.2008.02.007

[99] Muñoz-Muñoz, F., Ruiz, J.C., Alvarez-Lorenzo, C., Concheiro, A. and Bucio, E. (2012) Temperature- and pH-Sensitive Interpenetrating Networks Grafted onto PP: Cross-Linking Irradiation Dose as a Critical Variable for the Performance as Vancomycin-Eluting Systems. Radiation Physics and Chemistry, 81, 531-540. http://dx.doi.org/10.1016/j.radphyschem.2012.01.007

[100] Ruiz, J.C., Alvarez-Lorenzo, C., Taboada, P., Burillo, G., Bucio, E., De Prijck, K., Neils, H.J., Coenye, T. and Concheiro, A. (2008) Polypropylene Grafted with Smart Polymers (PNIPAAm/PAAc) for Loading and Controlled Release of Vancomycin. European Journal of Pharmaceutics and Biopharmaceutics, 70, 467-477. http://dx.doi.org/10.1016/j.ejpb.2008.05.020

[101] Meléndez-Ortiz, H.I., Díaz-Rodríguez, P., Alvarez-Lorenzo, C., Concheiro, A. and Bucio, E. (2014) Binary Graft Modification of Polypropylene for Anti-Inflammatory Drug-Device Combo Products. Journal of Pharmaceutical Sciences, 103, 1269-1277. http://dx.doi.org/10.1002/jps.23903

[102] Meléndez-Ortiz, H.I., Alvarez-Lorenzo, C., Concheiro, A. and Bucio, E. (2015) Grafting of N-Vinyl Caprolactam and Methacrylic Acid onto Silicone Rubber Films for Drug-Eluting Products. Journal of Applied Polymer Science, 132, Article ID: 41855. http://dx.doi.org/10.1002/app.41855

[103] Contreras-García, A., Bucio, E., Concheiro, A. and Alvarez-Lorenzo, C. (2010) Polypropylene Grafted with NIPAAm and APMA for Creating Hemocompatible Surfaces That Load/Elute Nalidixic Acid. Reactive and Functional Polymers, 70, 836-842. http://dx.doi.org/10.1016/j.reactfunctpolym.2010.07.019

[104] Contreras-García, A., Alvarez-Lorenzo, C., Taboada, C., Concheiro, A. and Bucio, E. (2011) Stimuli-Responsive Networks Grafted onto Polypropylene for the Sustained Delivery of NSAIDs. Acta Biomaterialia, 7, 996-1008. http://dx.doi.org/10.1016/j.actbio.2010.10.001

[105] Cole, I.S. (2014) 2-Smart Coatings for Corrosion Protection: An Overview. In: Makhlouf, A.S.H., Ed., Handbook of Smart Coatings for Materials Protection, Woodhead Publishing, New Delhi, 29-55. http://dx.doi.org/10.1533/9780857096883.1.29

[106] Liu, X., Li, H., Jin, Q. and Ji, J. (2014) Surface Tailoring of Nanoparticles via Mixed-Charge Monolayers and Their Biomedical Applications. Small, 10, 4230-4242.

[107] Kiryuhin, D.P., Kim, I.P., Buznik, V.M., Ignat'eva, L.N., Kuryavyi, V.G. and Sakharov, S.G. (2009) RadiationChemical Synthesis of Tetrafluoroethylene Telomers and Their Use for Preparation of Thin Protective Fluoropolymer Coatings. Russian Journal of General Chemistry, 79, 589-595. http://dx.doi.org/10.1134/S1070363209030402

[108] Manvi, G.N. and Jagtap, R.N. (2013) Radiation Cured Branched Polyurethane for Coatings. Pigment \& Resin Technology, 42, 309-316. http://dx.doi.org/10.1108/PRT-08-2010-0073

[109] Skorb, E.V. and Andreeva, D.V. (2013) Surface Nanoarchitecture for Bio-Applications: Self-Regulating Intelligent Interfaces. Advanced Functional Materials, 23, 4483-4506. http://dx.doi.org/10.1002/adfm.201203884

[110] Schulze, A., Maitz, M.F., Zimmermann, R., Marquardt, B., Fischer, M., Werner, C., Went, M. and Thomas, I. (2013) Permanent Surface Modification by Electron-Beam-Induced Grafting of Hydrophilic Polymers to PVDF Membranes. RSC Advances, 3, 22518-22526. http://dx.doi.org/10.1039/c3ra43659d

[111] Hidzir, N.M., Lee, Q., Hill, D.J.T., Rasoul, F. and Grøndahl, L. (2015) Grafting of Acrylic Acid-Co-Itaconic Acid onto PTFE and Characterization of Water Uptake by the Graft Copolymers. Journal of Applied Polymer Science, 132, Article ID: 41482. http://dx.doi.org/10.1002/app.41482

[112] Pierna, M., Santos, M., Arias, F.J., Alonso, M. and Rodríguez-Cabello, J.C. (2013) Efficient Cell and Cell-Sheet Harvesting Based on Smart Surfaces Coated with a Multifunctional and Self-Organizing Elastin-Like Recombinamer. Biomacromolecules, 14, 1893-1903. http://dx.doi.org/10.1021/bm400268v

[113] Hogg, A., Uhl, S., Feuvrier, F., Girardet, Y., Graf, B., Aellen, T., Keppner, H., Tardy, Y. and Burger, J. (2014) Protective Multilayer Packaging for Long-Term Implantable Medical Devices. Surface and Coatings Technology, 255, 124129. http://dx.doi.org/10.1016/j.surfcoat.2014.02.070

[114] Dai, G., Xiao, H., Zhu, S. and Shi, M. (2014) Collagen-Immobilized Poly(ethylene terephthalate)-g-Poly(vinyl alcohol) 
Fibers Prepared by Electron-Beam Co-Irradiation. Journal of Applied Polymer Science, 131, Article ID: 40597. http://dx.doi.org/10.1002/app.40597

[115] Yoshida, M., Langer, R., Lendlein, A. and Lahann, J. (2006) From Advanced Biomedical Coatings to Multi-Functionalized Biomaterials. Journal of Macromolecular Science, Part C, 46, 347-375. http://dx.doi.org/10.1080/15583720600945394

[116] Urban, M.W. (2006) Intelligent Polymeric Coatings; Current and Future Advances. Journal of Macromolecular Science, Part C, 46, 329-339. http://dx.doi.org/10.1080/15583720600945535

[117] Chilkoti, A. and Hubbell, J.A. (2005) Biointerface Science. MRS Bulletin, 30, 175-176. http://dx.doi.org/10.1557/mrs2005.48

[118] Lahann, J. and Langer, R. (2005) Smart Materials with Dynamically Controllable Surfaces. MRS Bulletin, 30, $185-188$. http://dx.doi.org/10.1557/mrs2005.50

[119] Senaratne, W., Andruzzi, L. and Ober, C.K. (2005) Self-Assembled Monolayers and Polymer Brushes in Biotechnology: Current Applications and Future Perspectives. Biomacromolecules, 6, 2427-2448. http://dx.doi.org/10.1021/bm050180a

[120] Bucio, E. and Burillo, G. (2009) Radiation-Induced Grafting of Sensitive Polymers. Journal of Radioanalytical and Nuclear Chemistry, 280, 239-243. http://dx.doi.org/10.1007/s10967-009-0505-9

[121] Higa, O.Z., Mendonça Faria, H.A. and de Queiroz, A.A.A. (2014) Polyglycerol Dendrimers Immobilized on Radiation Grafted Poly-HEMA Hydrogels: Surface Chemistry Characterization and Cell Adhesion. Radiation Physics and Chemistry, 98, 118-123. http://dx.doi.org/10.1016/j.radphyschem.2014.01.017

[122] Singh, H.D., Han, S.S., Son, J.H. and Kim, S.C. (2015) Poly(ethylene glycol) Dicarboxylate/Poly(ethylene oxide) Hydrogel Film Co-Crosslinked by Electron Beam Irradiation as an Anti-Adhesion Barrier. Materials Science and Engineering: C, 46, 195-201. http://dx.doi.org/10.1016/j.msec.2014.10.028

[123] Kim, S.J., Kim, W.I., Yamato, M., Okano, T., Kikuchi, A. and Kwon, O. (2013) Successive Grafting of PHEMA and PIPAAm onto Cell Culture Surface Enables Rapid Cell Sheet Recovery. Tissue Engineering and Regenerative Medicine, 10, 139-145. http://dx.doi.org/10.1007/s13770-013-0401-9

[124] Luk, J.Z., Cooper-White, J., Rintoul, L., Tarane, E. and Grøndahl, L. (2013) Functionalised Polycaprolactone Films and 3D Scaffolds via Gamma Irradiation-Induced Grafting. Journal of Materials Chemistry B, 1, 4171-4181. http://dx.doi.org/10.1039/c3tb20267d

[125] Gramm, S., Teichmann, J., Nitschke, M., Gohs, U., Eichhorn, K.J. and Werner, C. (2011) Electron Beam Immobilization of Functionalized Poly(vinyl methyl ether) Thin Films on Polymer Surfaces-Towards Stimuli Responsive Coatings for Biomedical Purposes. Express Polymer Letters, 5, 970-976. http://dx.doi.org/10.3144/expresspolymlett.2011.95

[126] Qu, X., Wirsén, A., Olander, B. and Albertsson, A.C. (2001) Surface Modification of High Density Polyethylene Tubes by Coating Chitosan, Chitosan Hydrogel and Heparin. Polymer Bulletin, 46, 223-229. http://dx.doi.org/10.1007/s002890170078

[127] Vázquez-González, B., Meléndez-Ortiz, H.I., Díaz-Gómez, L., Alvarez-Lorenzo, C., Concheiro, A. and Bucio, E. (2014) Silicone Rubber Modified with Methacrylic Acid to Host Antiseptic Drugs. Macromolecular Materials and Engineering, 299, 1240-1250. http://dx.doi.org/10.1002/mame.201300472

[128] Contreras-García, A., Bucio, E., Brackman, G., Coenye, T., Concheiro, A. and Alvarez-Lorenzo, C. (2011) Biofilm Inhibition and Drug-Eluting Properties of Novel DMAEMA-Modified Polyethylene and Silicone Rubber Surfaces. Biofouling, 27, 123-135. http://dx.doi.org/10.1080/08927014.2010.548115

[129] Muñoz-Muñoz, F., Bucio, E., Magariños, B., Concheiro, A. and Alvarez-Lorenzo, C. (2014) Temperature- and pHSensitive IPNs Grafted onto Polyurethane by Gamma Radiation for Antimicrobial Drug-Eluting Insertable Devices. Journal of Applied Polymer Science, 131, Article ID: 39992.

[130] Luna-Straffon, M.A., Contreras-García, A., Brackman, G., Coenye, T., Concheiro, A., Alvarez-Lorenzo, C. and Bucio, E. (2014) Wound Debridement and Antibiofilm Properties of Gamma-Ray DMAEMA-Grafted onto Cotton Gauzes. Cellulose, 21, 3767-3779. http://dx.doi.org/10.1007/s10570-014-0371-7 